\title{
Association Between Smoking and COVID-19 Severity: Evidence from Bangladesh
}

\author{
Faroque Md Mohsin (D) ${ }^{1, *}$ \\ Tajrin Tahrin Tonmon (iD) ${ }^{2, *}$ \\ Ridwana Nahrin (iD) ' \\ Sharmin Ahmed Tithy ${ }^{2}$ \\ Farzana Akter Ame' \\ Ismot $\mathrm{Ara}^{3}$ \\ SK Tasnuva Alam ${ }^{4}$ \\ Abu Muhammad Abdullah Pervej ${ }^{5}$ \\ Md Shahjalal (iD) ' \\ Mohammad Delwer Hossain \\ Hawlader (iD ${ }^{2}$ \\ 'Civil Surgeon Office, Azimpur, Dhaka, \\ 1205, Bangladesh; ${ }^{2}$ Department of Public \\ Health, North South University, \\ Bashundhara, Dhaka, 1229, Bangladesh; \\ ${ }^{3}$ Community Medicine, Shaheed \\ Suhrawardy Medical College, Dhaka, \\ 1207, Bangladesh; ${ }^{4}$ Azimpur School \\ Health Clinic, Azimpur, Dhaka, I205, \\ Bangladesh; ${ }^{5}$ Anaesthesiology, National \\ Institute of Traumatology and \\ Orthopedic Rehabilitation (NITOR), \\ Dhaka, I207, Bangladesh \\ *These authors contributed equally to \\ this work
}

Purpose: Previous studies have explored several risk factors for coronavirus disease 2019 (COVID-19) severity, but there is still a lack of association with smoking. Our study aims to find out the association between smoking and COVID-19 severity.

Subjects and Methods: This comparative study was conducted among hospitalized severely and critically ill COVID-19 patients, as well as asymptomatic, mild, and moderate patients from the list of the city corporation (Dhaka, Bangladesh), as confirmed by reversetranscription polymerase chain reaction (RT-PCR). A total of 2022 adults aged $\geq 18$ years were enrolled in this study.

Results: The mean age of the patients was 41.17 years; $66.96 \%$ of the patients were male, $57.02 \%$ were aged above 35 years, and $81.50 \%$ of the patients had ever been married; and $33.09 \%$ cases were mild and $14.99 \%$ were severe. Among the patients, $29.4 \%$ were eversmokers. Smoking status, duration, and frequency, and the presence of comorbidities were significantly associated with COVID-19 severity $(p<0.001)$. Ever-smokers were 1.35 times (95\% CI: $0.74-2.45), 1.30$ times (95\% CI: $0.58-2.87)$, and 2.45 times (95\% CI: $1.07-5.61)$ more likely to be mild, severe, and critical cases in comparison to non-smokers.

Conclusion: This study revealed a strong association between smoking and COVID-19 severity that calls for mass awareness and cessation campaigns from governments and voluntary organizations.

Keywords: COVID-19, smoking, ICU, RT-PCR, Bangladesh

\section{Introduction}

The emergence of viral disease has always been a serious threat to public health. Over the past two decades, the emergence of severe acute respiratory syndrome coronavirus (SARS-CoV) from 2002-2003 and H1N1 influenza in 2009 were two big threats to the world in the form of an epidemic and a pandemic. ${ }^{1}$ Currently, the world is facing another viral disease, coronavirus disease 2019 (COVID-19), which was announced as a pandemic by the World Health Organization (WHO) on March 11, 2020. According to the Centers for Disease Control and Prevention (CDC, 2020), the characteristics of people who are at risk of suffering severe illness from COVID-19 are people aged over 65 years; people living in a long-term care facility; people with asthma, diabetes, kidney disease, liver disease, or heart disease; people who have immunodeficiency as a result of disease; and people who have unhealthy behavior, such as smoking. ${ }^{2-6}$

According to the WHO factsheet (2020), globally, more than 8 million people die of tobacco smoking every year, of whom 7 million are direct smokers and 1.2 million are second-hand smokers. ${ }^{4}$ Since COVID-19 has a severe stage of 
pneumonia or respiratory failure, smokers are much susceptible to severe disease because of their immunocompromised lungs. ${ }^{7}$ In an article from the area of pulmonology, Brake et al explained the biological process of coronavirus attacking the human body, where they stated that smoking is one factor that accelerates the production of the angiotensin-converting enzyme-2 (ACE2) receptor, which is known to be the receptor of coronavirus, and therefore smokers are more vulnerable to this disease than non-smokers. ${ }^{8,9}$ Reviewing seven study reports, Zhao et al concluded that although the association between smoking and COVID-19 is non-significant, active smoking increases the risk of having severe COVID-19 and smokers have 1.98 times greater risk of having the severe stage. $^{10}$

In an evidence-based study conducted in Bangladesh from 2009 to 2012, Nargis et al found that 23\% of adults above 15 years of age are smokers, while in another study, the prevalence of second-hand smokers who are exposed to smoking at home was found to be $53.5 \%{ }^{11,12}$ With such a large group of direct and indirect smokers, Bangladesh is at risk of having a high death toll from COVID-19, according to studies on the association between smoking and the severity of COVID-19. ${ }^{13}$ But there is still no evidence on how many of the cases or deaths are accompanied by severe pneumonia or acute respiratory disease syndrome caused by smoking. ${ }^{14}$ If this information could be retrieved, a smoking cessation campaign could be emphasized as an initial measure to reduce the death toll in the future. Since no research has been conducted on this issue so far, to lessen this knowledge gap and to assess the true magnitude of the problem, this research is much needed in the current situation. Therefore, our aim was to explore the association between smoking and the severity of COVID-19 in Bangladesh.

\section{Materials and Methods Study Design}

This was a comparative study where the data were collected both from hospitals in Dhaka and by telephone interviews with COVID-19-positive patients, whose status was confirmed by reverse-transcription polymerase chain reaction (RT-PCR). The total sample size of the study was 2022, comprising 355, 669, 361, 303, and 334 samples for the asymptomatic, mild, moderate, severe, and critical categories, respectively. This was determined using the formula of sample size calculation in a comparative study setting using $80 \%$ power. Hospitals were chosen conveniently from where the severe and critical patients were selected for interviews. For asymptomatic, mild, and moderate cases, interviews were conducted over telephone following the list collected from city corporation booths in Dhaka. Adult patients of 18 years of age and above were included in this study.

\section{Measures}

In accordance with the Bangladesh Society of Medicine, COVID-19 cases were categorized as asymptomatic, mild, moderate, severe, and critical. ${ }^{15}$ According to the guideline from the $\mathrm{CDC}$, only people who have smoked at least 100 cigarettes and are still continuing to smoke were considered as smokers, ${ }^{5}$ and those who have smoked fewer than 100 cigarettes ever were considered as nonsmokers. The information on smoking was collected by asking questions of the study population, mainly focusing on whether they have ever smoked cigarettes, and the responses were coded as non-smokers $=0$ and eversmokers $=1$. All of these queries were asked of all the study population, and the categories were determined by taking ideas from the mentioned guidelines and previously published studies. ${ }^{5}$

\section{Statistical Analysis}

STATA version 16 was used for analyzing the data. Descriptive statistics were reported as frequency and percentage to characterize the demographic profile of the study sample. Differences in socio-demographic factors between the five COVID-19-positive groups were presented using the chi-squared test. For univariate analysis of continuous variables, $t$-test and one-way ANOVA were performed. A multinomial logistic regression analysis was also performed to assess the effects of risk factors on the severity of COVID-19. The associations between exposure to smoking and COVID-19 severity outcomes and the effects of the potential risk factors on COVID-19 severity were investigated using both univariable and multivariable logistic regression models. The univariate or unadjusted models included only one exposure variable and the outcome variable each time for all the potential risk factors. Then, these associations were progressively adjusted for potential confounders in the multivariable (multinomial logistic regression) model, including 11 risk factors: gender, age, marital status, educational level, ethnicity, occupation, residence type, smoking status, years of smoking, numbers of cigarettes smoked in total, and comorbidities. 
(Only statistically significant $[p<0.05]$ variables found in the univariate analysis of the chi-square test were included.) Results were reported as adjusted odds ratios (AORs) with $95 \%$ confidence intervals (CIs). All statistical tests were two sided, and a $p$-value $<0.05$ was considered statistically significant.

\section{Ethics}

All the procedures were conducted following the ethical guidelines of the institution's review board (IRB)/ethical review committee (ERC) of North South University, Bangladesh (Memo no. 2020/OR-NSU/IRB-No. 0802). The ethical standards laid down in the 1964 Declaration of Helsinki and its later amendments or comparable ethical standards were followed wherever applicable. During the face-to-face interview, informed written consent was obtained from all the participants involved in the study. However, electronic consent was attached to the webbased questionnaire, where the nature, purpose, and objective of the study were clearly stated, along with the declaration of confidentiality and anonymity.

\section{Results}

Among all 2022 COVID-19 patients, $16.52 \%$ of patients were critical, $14.99 \%$ were severe, $17.85 \%$ were moderate, $33.09 \%$ were mild, and $17.56 \%$ were asymptomatic. The mean age of the patients was $41.17 \pm 15.11$ years. Overall, $66.96 \%$ of the patients were males and $57.02 \%$ were aged above 35 years; $33.58 \%$ of the patients had studied to higher secondary level, $32.05 \%$ of the patients were office employees; the majority $(81.50 \%)$ of the patients had ever been married, $70.82 \%$ of the patients were living in urban residential areas, most of them $(95.10 \%)$ were Bengali, and most (91.59\%) were Muslim (Table 1).

In the bivariate associations of COVID-19 severity outcomes with socio-demographic characteristics by each sub-domain, it was observed that gender $\left(\chi^{2}=15.81\right.$, $p=0.003)$, age $\left(\chi^{2}=256.70, p<0.001\right)$, marital status $\left(\chi^{2}=183.82, \quad p<0.001\right)$, educational level $\left(\chi^{2}=115.63\right.$, $p<0.001)$, occupation $\left(\chi^{2}=237.32, p<0.001\right)$, residential status $\left(\chi^{2}=126.56, p<0.001\right)$, and ethnicity $\left(\chi^{2}=18.20\right.$, $p=0.001$ ) were significantly associated with COVID-19 severity. Comparing the mean differences between the case type of COVID-19 with patients' age, the mean age of the COVID-positive patients $(41.17 \pm 15.11$ years $)$ was also significantly different among the five types of COVID-19 groups (95\% CI: 17.86-22.80; $p<0.001)$.
The results from bivariate associations of COVID-19 severity outcomes with behavioral factors and comorbidities are presented in Table 2. Among the COVIDpositive patients, $29.4 \%$ were ever-smokers, of whom $6.92 \%$ of patients had smoked for more than 25 years in their lives and $28.68 \%$ had smoked at least 100 cigarettes in their lives. Among all the behavioral factors, smoking status $\left(\chi^{2}=38.88, \quad p<0.001\right)$, duration of smoking $\left(\chi^{2}=442.99, p<0.001\right)$, frequency of cigarettes smoked $\left(\chi^{2}=58.16, p<0.001\right)$, and having any other diseases $\left(\chi^{2}=472.01, p<0.001\right)$ were significantly associated with COVID-19 severity. The prevalence of having any other diseases was $46.24 \%$ for the study participants. Comparing the mean differences between the case type of COVID-19 with the frequency of cigarette smoking years, the average number of cigarette smoking years $(5.25 \pm 10.20)$ was found to be significantly different among the five case types (95\% CI: 1.03-10.01; $p<0.001$ ) (Table 2).

Figure 1 shows the distribution of COVID-19 severity among the ever-smokers and non-smokers. More severe and critical cases were ever-smokers, at $20.37 \%$ and $18.86 \%$, respectively, whereas it was found that $12.75 \%$ and $15.55 \%$ of severe and critical patients, respectively, were non-smokers.

The overall results of the multinomial logistic regression analysis of the effect of the potential risk factors on the development of COVID-19 severity among the COVID-positive patients are presented in Table 3. In this model, only the variables found to be statistically significant $(p<0.05)$ in the bivariate analysis were included. Therefore, the multinomial logistic regression analysis used 11 risk factors (gender, age, marital status, education, ethnicity, occupation, residency, smoking status, years of smoking, number of cigarettes smoked in total, and comorbidities) and their effects on COVID-positive case types.

Among all the COVID-positive patients, those who were ever-smokers at some point in their lives were 1.35 times (95\% CI: 0.74-2.45), 1.30 times (95\% CI: $0.58-$ 2.87), and 2.45 times (95\% CI: $1.07-5.61)$ more likely to be mild, severe, and critical COVID patients, respectively, compared to those who were non-smokers, but eversmoker patients were 0.96 times (95\% CI: 0.48-1.90) less likely to be moderate patients compared to those who were non-smokers, after adjusting all other covariates.

It was found that females were 1.10 times more likely to be mild COVID patients compared to males 
Table I Association of Socio-Demographic Factors with COVID-19 Severity and Their Sample Distribution

\begin{tabular}{|c|c|c|c|c|c|c|c|}
\hline \multirow[t]{2}{*}{ Variables } & \multirow[t]{2}{*}{ Total, n (\%) } & \multicolumn{5}{|c|}{ Type of COVID-19 Case } & \multirow[t]{2}{*}{$p$-Value } \\
\hline & & $\begin{array}{c}\text { Asymptomatic, } \\
\text { n (\%) }\end{array}$ & $\begin{array}{l}\text { Mild, } \\
\text { n (\%) }\end{array}$ & $\begin{array}{l}\text { Moderate, } \\
\text { n (\%) }\end{array}$ & $\begin{array}{l}\text { Severe, } \\
\text { n (\%) }\end{array}$ & $\begin{array}{l}\text { Critical, } \\
\text { n (\%) }\end{array}$ & \\
\hline Overall & $2022(100)$ & 355 (17.56) & $669(33.09)$ & $361(17.85)$ & $303(14.99)$ & 334 (16.52) & - \\
\hline \multicolumn{8}{|l|}{ Gender } \\
\hline Male & $1354(66.96)$ & $228(16.84)$ & $425(31.39)$ & $243(17.95)$ & $206(15.21)$ & $252(18.61)$ & $0.003^{*}$ \\
\hline Female & $668(33.04)$ & $127(19.01)$ & $244(36.53)$ & $118(17.66)$ & $97(14.52)$ & $82(12.28)$ & \\
\hline $\begin{array}{l}\text { Age (years), mean } \\
\pm \text { SD }[95 \% \mathrm{Cl}]\end{array}$ & $\begin{array}{l}41.17 \pm 15.11 \\
{[17.86-22.80]}\end{array}$ & $\begin{array}{l}36.83 \pm 10.68 \\
{[11.33-|6.4|]}\end{array}$ & $\begin{array}{l}32.01 \pm 9.95 \\
{[5.49-9.72]}\end{array}$ & $\begin{array}{c}39.62 \pm 13.14 \\
{[16.44-20.93]}\end{array}$ & $\begin{array}{c}50.70 \pm 13.52 \\
{[22.97-27.32]}\end{array}$ & $\begin{array}{l}57.16 \pm 13.54 \\
{[15.08-20.00]}\end{array}$ & $<0.001 *$ \\
\hline \multicolumn{8}{|l|}{ Age (years) } \\
\hline$\leq 35$ & 869 (42.98) & $128(14.73)$ & $445(51.21)$ & $103(11.85)$ & $60(6.90)$ & $133(15.30)$ & $<0.001 *$ \\
\hline$>35$ & II 53 (57.02) & $227(19.69)$ & $224(19.43)$ & $258(22.38)$ & $243(21.08)$ & $201(17.43)$ & \\
\hline \multicolumn{8}{|l|}{ Marital status } \\
\hline Ever married & $1648(81.50)$ & $279(16.93)$ & $455(27.61)$ & $297(18.02)$ & $288(17.48)$ & $329(19.96)$ & $<0.001 *$ \\
\hline Never married & $374(18.50)$ & $76(20.32)$ & $214(57.22)$ & 64 (17.1I) & $15(4.01)$ & $5(1.34)$ & \\
\hline \multicolumn{8}{|l|}{ Educational level } \\
\hline Primary or below & $267(13.20)$ & $48(17.98)$ & 113 (42.32) & $55(20.60)$ & $26(9.74)$ & $25(9.36)$ & $<0.001 *$ \\
\hline Secondary & $466(23.05)$ & 117 (25.1I) & $|4|(30.26)$ & $92(19.74)$ & $60(12.88)$ & $56(12.02)$ & \\
\hline Higher secondary & 679 (33.58) & $132(19.44)$ & $216(31.81)$ & I 34 (19.73) & $85(12.52)$ & II2 (16.49) & \\
\hline Graduate and above & $610(30.17)$ & $58(9.5 \mathrm{I})$ & $199(32.62)$ & $80(13.11)$ & $132(2 \mid .64)$ & $14 \mid(23.11)$ & \\
\hline \multicolumn{8}{|l|}{ Occupation } \\
\hline Office employee & 648 (32.05) & $104(16.05)$ & II (32.87) & $112(17.28)$ & 109 (16.82) & $110(16.98)$ & $<0.001 *$ \\
\hline Police officer & $63(3.12)$ & $9(14.29)$ & $16(25.40)$ & $20(31.75)$ & $13(20.63)$ & $5(7.94)$ & \\
\hline Business & $560(27.70)$ & $120(21.43)$ & $188(33.57)$ & $102(18.21)$ & $68(12.14)$ & $82(14.64)$ & \\
\hline Homemaker & $302(14.94)$ & $54(17.88)$ & $86(28.48)$ & $53(17.55)$ & $54(17.88)$ & $55(|8.2|)$ & \\
\hline Medical professional & $49(2.42)$ & $8(16.33)$ & $23(46.94)$ & $8(16.33)$ & $5(10.20)$ & $5(10.20)$ & \\
\hline Unemployed & $283(14.00)$ & $40(14.13)$ & I27 (44.88) & $44(15.55)$ & $48(16.96)$ & $24(8.48)$ & \\
\hline Retired & $63(3.12)$ & $3(4.76)$ & $2(3.17)$ & $5(7.94)$ & $6(9.52)$ & $47(74.60)$ & \\
\hline Others & $54(2.67)$ & $17(31.48)$ & $14(25.93)$ & $17(31.48)$ & $0(0.00)$ & $6(11.11)$ & \\
\hline \multicolumn{8}{|l|}{ Residence type } \\
\hline Urban-residential & $1432(70.82)$ & $283(19.76)$ & $4 \mid 3(28.84)$ & $28 \mid(19.62)$ & $246(17.18)$ & 209 (14.59) & $<0.001 *$ \\
\hline Urbannon-residential & $415(20.52)$ & $47(11.33)$ & $|7|(4 \mid .20)$ & $61(14.70)$ & $36(8.67)$ & $100(24.10)$ & \\
\hline Urban-slum & 75 (3.7I) & $12(16.00)$ & $52(69.33)$ & $8(10.67)$ & $3(4.00)$ & $0(0.00)$ & \\
\hline Rural & $100(4.95)$ & $13(13.00)$ & $33(33.00)$ & $11(11.00)$ & $18(18.00)$ & $25(25.00)$ & \\
\hline \multicolumn{8}{|l|}{ Ethnicity } \\
\hline Bengali & $1923(95.10)$ & $349(18.15)$ & 639 (33.23) & 345 (17.94) & $284(14.77)$ & $306(15.91)$ & $0.001 *$ \\
\hline Chakma/others & $99(4.90)$ & $6(6.06)$ & $30(30.30)$ & $16(16.16)$ & $19(19.19)$ & $28(28.28)$ & \\
\hline \multicolumn{8}{|l|}{ Religion } \\
\hline Muslim & $1852(91.59)$ & $330(17.82)$ & $613(33.10)$ & $333(17.98)$ & $269(14.52)$ & 307 (16.58) & 0.382 \\
\hline Hindu & $150(7.42)$ & $23(15.33)$ & $49(32.67)$ & $25(16.67)$ & $32(21.33)$ & $21(14.00)$ & \\
\hline Buddhist & $15(0.74)$ & $2(13.33)$ & $6(40.00)$ & I (6.67) & I (6.67) & $5(33.33)$ & \\
\hline Christian & $5(0.25)$ & $0(0.00)$ & I (20.00) & $2(40.00)$ & I (20.00) & I (20.00) & \\
\hline
\end{tabular}

Note: ${ }^{*} p$-Value significant at the $<0.05$ level. 
Table 2 Association of Behavioral Factors and Other IIInesses with COVID-19 Severity and Their Sample Distribution

\begin{tabular}{|c|c|c|c|c|c|c|c|}
\hline \multirow[t]{2}{*}{ Variables } & \multirow[t]{2}{*}{ Total, n (\%) } & \multicolumn{5}{|c|}{ Type of COVID-19 Case } & \multirow[t]{2}{*}{$p$-Value } \\
\hline & & $\begin{array}{c}\text { Asymptomatic, } \\
\text { n (\%) }\end{array}$ & $\begin{array}{l}\text { Mild, } \\
\text { n (\%) }\end{array}$ & $\begin{array}{l}\text { Moderate, } \\
\text { n (\%) }\end{array}$ & $\begin{array}{c}\text { Severe, } \\
\text { n (\%) }\end{array}$ & $\begin{array}{c}\text { Critical, } \\
\text { n (\%) }\end{array}$ & \\
\hline Overall & $2022(100)$ & $355(17.56)$ & 669 (33.09) & $36 \mid(17.85)$ & $303(14.99)$ & $334(16.52)$ & - \\
\hline \multicolumn{8}{|l|}{ Smoking status } \\
\hline Ever-smoker & $594(29.38)$ & $72(12.12)$ & $203(34.18)$ & $86(14.48)$ & $12 \mid(20.37)$ & $112(18.86)$ & $<0.001 *$ \\
\hline Non-smoker & $1428(70.62)$ & $283(19.82)$ & $466(32.63)$ & $275(19.26)$ & $182(12.75)$ & $222(15.55)$ & \\
\hline $\begin{array}{l}\text { Smoking (years) mean } \\
\pm \mathrm{SD}[95 \% \mathrm{Cl}]\end{array}$ & $\begin{array}{c}5.25 \pm 10.20 \\
{[1.03-10.01]}\end{array}$ & $\begin{array}{c}2.25 \pm 5.52[6.30- \\
10.38]\end{array}$ & $\begin{array}{c}2.52 \pm 5.20 \\
{[6.26-9.88]}\end{array}$ & $\begin{array}{c}4.12 \pm 8.45 \\
{[4.43-8.50]}\end{array}$ & $\begin{array}{l}10.59 \pm 13.55 \\
{[4.43-8.50]}\end{array}$ & $\begin{array}{l}10.27 \pm 14.96 \\
{[4.16-8.13]}\end{array}$ & $<0.001 *$ \\
\hline \multicolumn{8}{|c|}{ Smoking duration (years) } \\
\hline $\mathrm{I}-5$ & $139(6.87)$ & $32(23.02)$ & $76(54.68)$ & $26(18.7 I)$ & $5(3.60)$ & $0(0.00)$ & $<0.001 *$ \\
\hline $6-10$ & $127(6.28)$ & $24(18.90)$ & 81 (63.78) & $12(9.45)$ & $8(6.30)$ & $2(1.57)$ & \\
\hline $11-15$ & 81 (4.0I) & $14(17.28)$ & $24(29.63)$ & $18(22.22)$ & $18(22.22)$ & $7(8.64)$ & \\
\hline $16-20$ & $88(4.35)$ & 7 (7.95) & 7 (7.95) & $19(21.59)$ & 35 (39.77) & $20(22.73)$ & \\
\hline $21-25$ & $59(2.92)$ & $2(3.39)$ & $7(11.86)$ & $8(13.56)$ & $25(42.37)$ & $17(28.81)$ & \\
\hline$>25$ & $140(6.92)$ & $3(2.14)$ & $4(2.86)$ & $16(11.43)$ & $46(32.86)$ & $7 \mid(50.71)$ & \\
\hline None & I388 (68.64) & $273(19.67)$ & $470(33.86)$ & $262(18.88)$ & $166(11.96)$ & $217(15.63)$ & \\
\hline \multicolumn{8}{|l|}{ Cigarette smoking } \\
\hline$\geq 100$ cigarettes & $580(28.68)$ & $66(11.38)$ & I $87(32.24)$ & $96(16.55)$ & $124(21.38)$ & $107(18.45)$ & $<0.001 *$ \\
\hline$<100$ cigarettes & $64(3.17)$ & $2(3.13)$ & $27(42.19)$ & $13(20.31)$ & $13(20.31)$ & $9(14.06)$ & \\
\hline No & $1378(68.15)$ & $287(20.83)$ & $455(33.02)$ & $252(18.29)$ & $166(12.05)$ & $218(15.82)$ & \\
\hline \multicolumn{8}{|l|}{ Comorbidities } \\
\hline Yes & 935 (46.24) & $113(12.09)$ & $163(17.43)$ & $146(15.61)$ & $227(24.28)$ & $286(30.59)$ & $<0.001 *$ \\
\hline No & $1087(53.76)$ & $242(22.26)$ & $506(46.55)$ & $215(19.78)$ & 76 (6.99) & $48(4.42)$ & \\
\hline
\end{tabular}

Note: ${ }^{*} p$-Value is significant at the $<0.05$ level.

(95\% CI: 0.83-1.47), but when exploring the effect by gender in other subdomains, we did not observe significant associations between females and COVID-19 severity; rather, they were less likely to be moderate (AOR: 0.91; 95\% CI: 0.66-1.24), severe (AOR: 0.95; 95\% CI: 0.66-1.38), and critical (AOR: 0.68; 95\% CI: 0.46-1.01) patients, respectively. Ever-married patients were 1.18 times (95\% CI: $0.80-1.75), 2.85$ times $(95 \%$ CI: $1.53-5.31$ ), and 9.88 times (95\% CI: 3.69-26.42) more likely to be moderate, severe, and critical COVID patients, respectively, compared to the never-married ones. Those who were aged more than 35 years were 1.53 times (95\% CI: $1.08-2.17)$ and 2.06 times (95\% CI: 1.37-3.11) more likely to be moderate and severe patients, respectively, compared to those who were not.

Regarding the educational background of the patients, graduates and above were 1.81 times (95\% CI: 1.07-3.08),
2.61 times (95\% CI: $1.33-5.12)$, and 2.39 times $(95 \%$ CI: 1.19-4.78) more likely to be mild, severe, and critical cases compared to those who had studied to primary level or below, respectively. Also, patients with higher secondary level education were 1.24 times (95\% CI: 0.64-2.40) more likely to be critical patients. Both significant effects and associations were found between ethnicity and severe or critical positive COVID cases (severe, AOR: 3.48; 95\% CI: 1.26-9.58; critical, AOR: 3.23; 95\% CI: 1.17-8.94) for Chakma and other ethnic groups, compared to the Bengali COVID cases.

When observing the effects of occupation on COVID19 severity, it was reported that police officers were 2.09 times (95\% CI: $0.58-7.55)$ and retired people were 1.67 times (95\% CI: $0.28-9.90)$ more likely to be moderate COVID patients compared to medical professionals. For the severe group of patients, office employees were 1.56 
$40.00 \%$

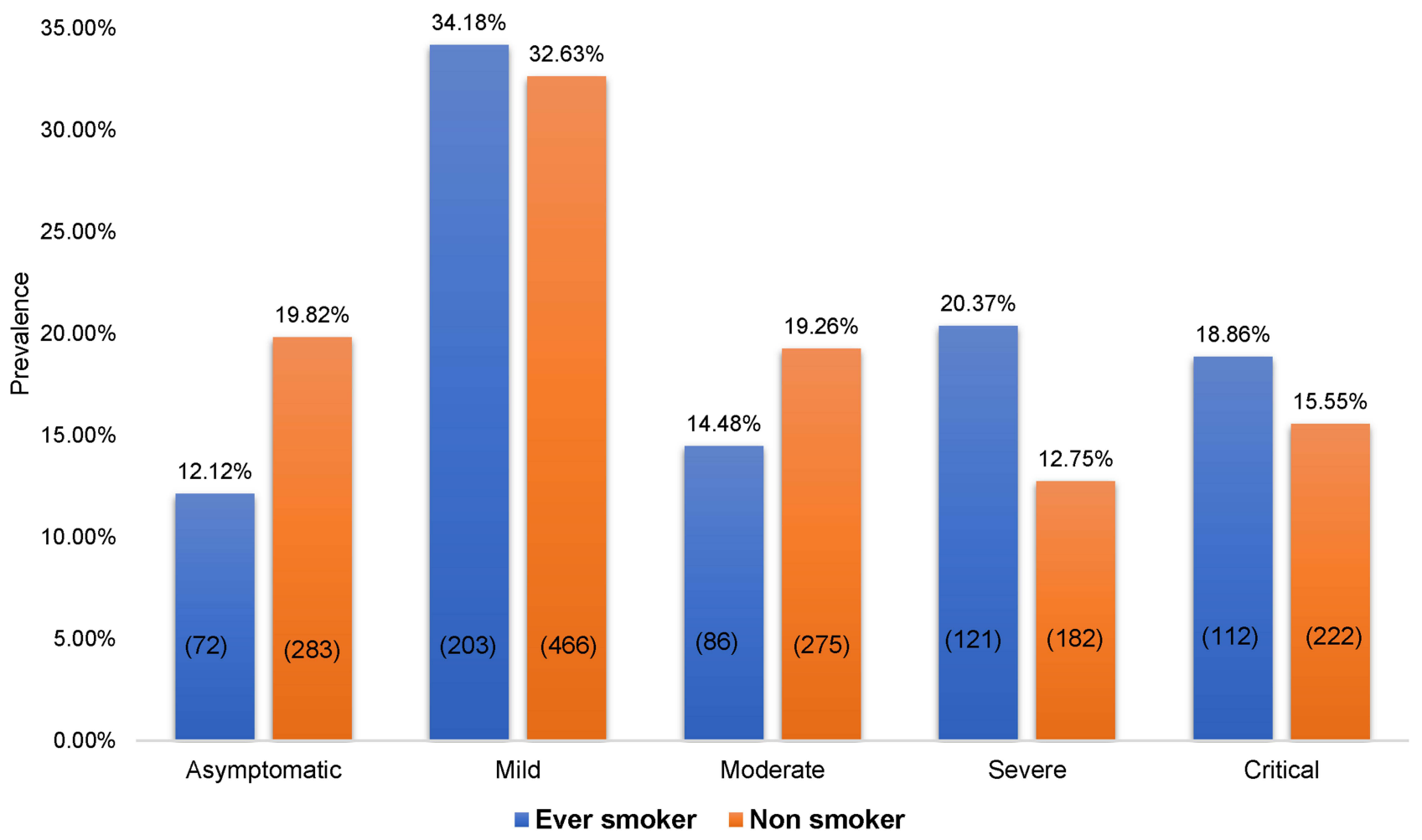

Figure I Disparities n COVID-19 severity between the smoker types.

times (95\% CI: 0.44-5.49), police officers were 2.22 times (95\% CI: 0.49-10.10), and unemployed patients were 2.02 times (95\% CI: $0.54-7.53)$ more likely to be severe cases. Among the critical cases, office employees were 1.90 (95\% CI: 0.53-6.81) times, homemakers were 2.05 times (95\% CI: $0.55-7.63)$, and retired people were 13.73 times (95\% CI: 2.29-82.17) more likely to be critical COVID patients.

Residents of non-residential urban localities were 1.81 times (95\% CI: 1.23-2.66), urban slums were 2.45 times (95\% CI: 1.16-5.19), and rural areas were 1.86 times (95\% CI: 0.91-3.82) more likely to be mild COVID patients compared to residents of residential urban localities. Likewise, patients living in non-residential urban areas were 1.38 times (95\% CI: $0.89-2.16$ ) more likely to be moderate COVID patients and they were also 1.06 times (95\% CI: $0.63-1.78)$ and rural residents were 1.57 times (95\% CI: 0.68-3.62) more likely to be severe patients compared to the residents of urban localities. Nonresidential urban residents were 2.91 times (95\% CI: 1.82
4.67) and rural residents were 2.19 times (95\% CI: 0.964.97) more likely to be critical COVID patients.

When observing the effect of smoking duration and development of COVID-19 severity, significant effects of more than 25 years of smoking on becoming moderate COVID patients (AOR: 4.45 ; 95\% CI: 1.17-16.99), severe COVID patients (AOR: 8.85; 95\% CI: 2.36-33.25), and critical COVID patients (AOR: 6.52; 95\% CI: 1.71-24.90) were found, for the development of disease severity, and all the estimates were significantly associated. Patients who had smoked at least 100 cigarettes in their lives were 1.63 times (95\% CI: 1.14-2.34), 1.58 times (95\% CI: 1.06-2.36), 2.15 times (95\% CI: 1.39-3.33), and 1.80 times (95\% CI: 1.16-2.82) more likely to be mild, moderate, severe, and critical COVID patients, respectively, compared to those who had never smoked.

When exploring the effect estimate between comorbidities and all the subdomains of COVID-19 severity, no significant effect of comorbidities was found for mild cases (AOR: 0.66; 95\% CI: 0.48-0.90), but the effect 


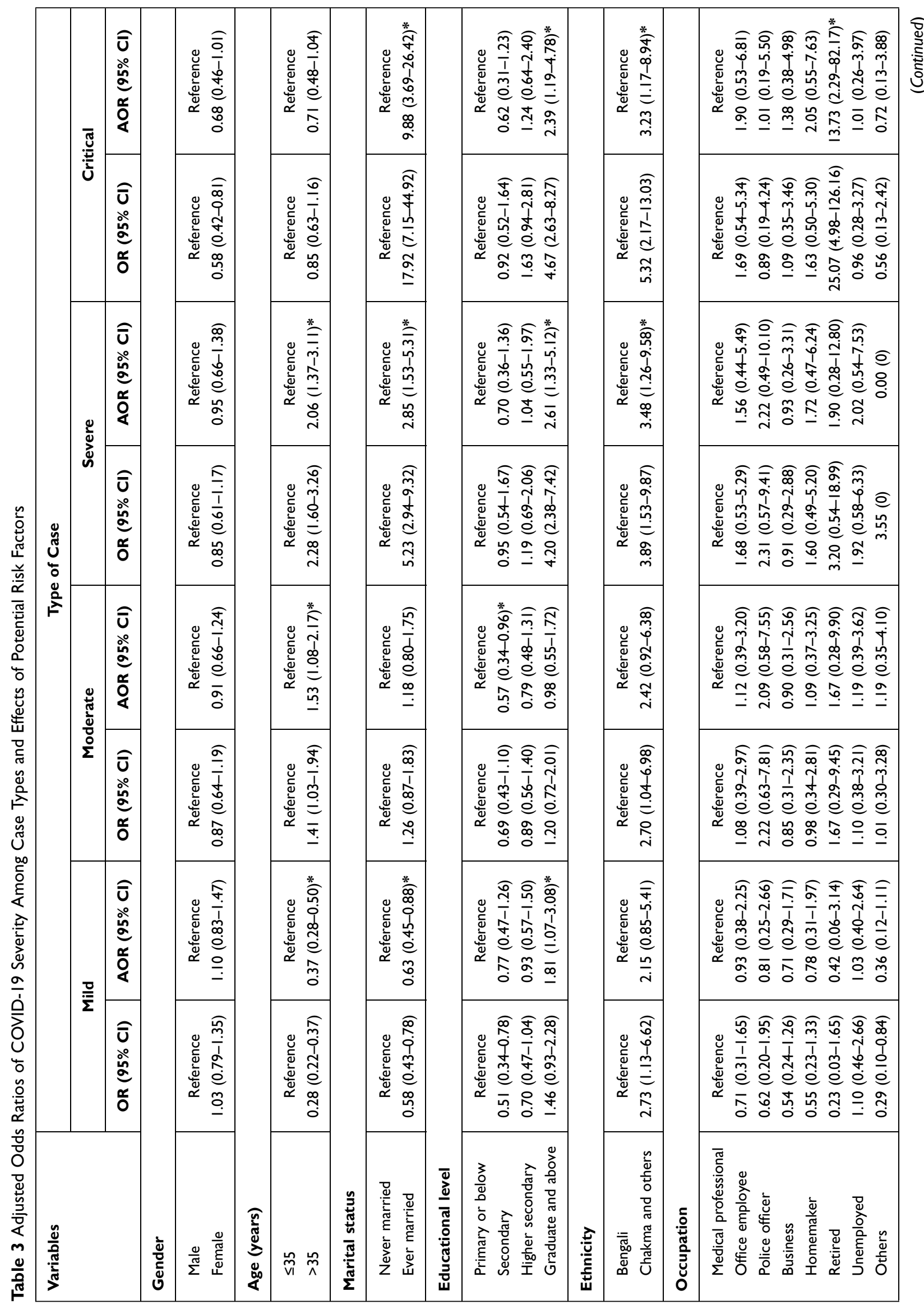




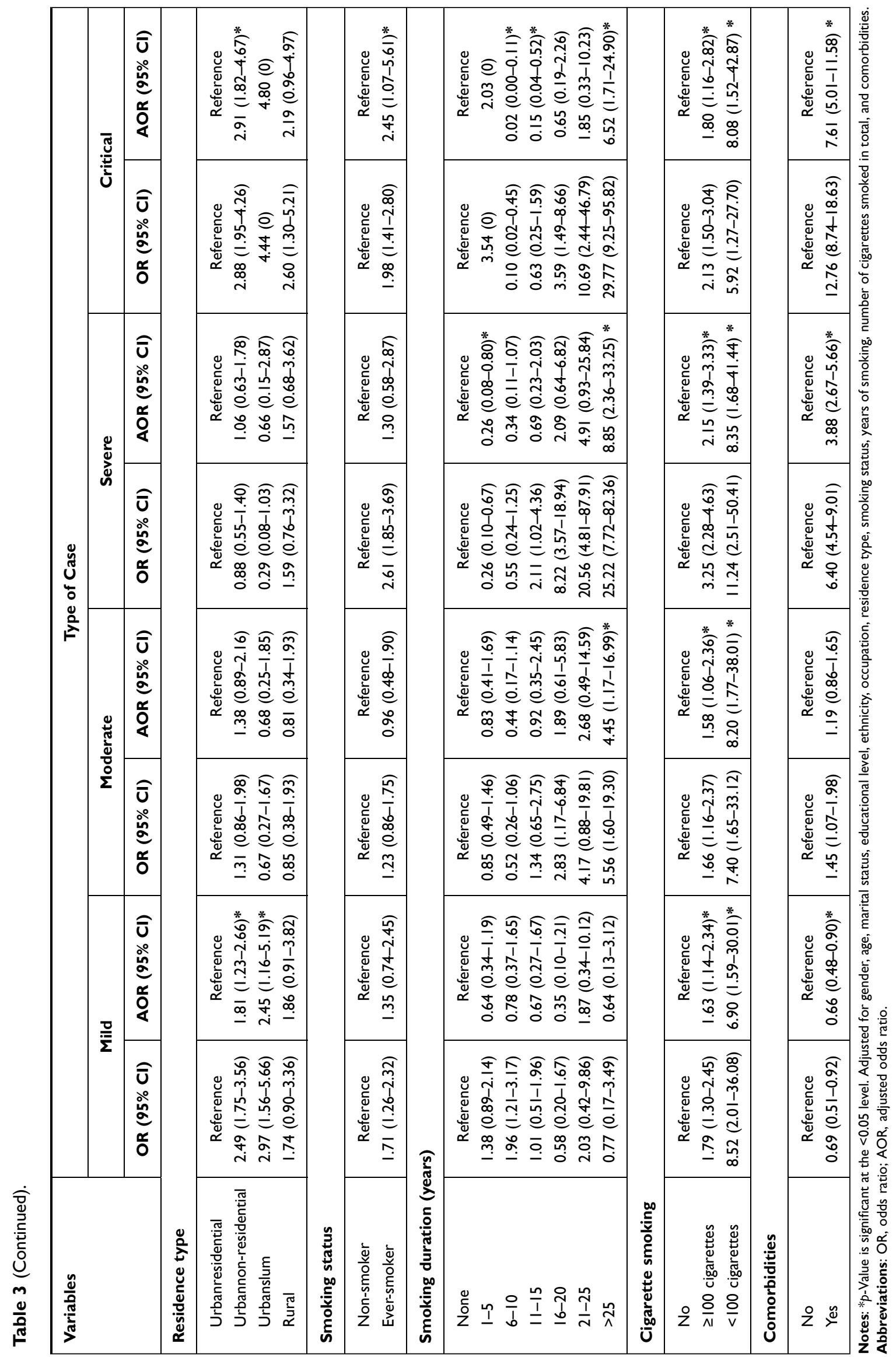


estimate was 1.19 times for moderate (AOR: 1.19; 95\% CI: 0.86-1.65), 3.88 times for severe (AOR: 3.88 ; 95\% CI: 2.67-5.66), and 7.61 times for critical (AOR: 7.61, 95\% CI: 5.01-11.58) COVID patients, respectively, which is why the effect of the main exposure, smoking status of the patients, was observed after adjusting this potential confounder.

\section{Discussion}

This study provides evidence that smoking fuels the progression of COVID-19 severity. Analysis shows that eversmokers are at 2.45 times higher risk of having critical condition than never-smokers, which complies with the previous research conducted by the CDC COVID-19 Response Team in the USA in $2020,{ }^{5}$ and many other studies conducted in China. ${ }^{10,16-18}$ The study results also show that smokers with a longer active smoking history are more prone to developing the severe and critical stages of COVID-19, which is a new finding compared to other COVID-19 and smoking-related studies.

In the demographic factor analysis, age, gender, educational status, ethnicity, marital status, residential type, and occupation were significantly associated with COVID-19 severity. Here, it was found that cases aged more than 35 years suffered from a more severe state than people below this age. Although the CDC marked elderly people ( $>60$ years) as the vulnerable group, ${ }^{5}$ studies have also found that younger and older adults are the groups with most exposure and increased numbers of cases. ${ }^{19-21}$ According to these studies, adults are exposed at their workplace, during transportation, or at other gatherings, as they are the main earners in their families. Also, above 35 years of age is considered to be a potential stage for developing non-communicable diseases, ${ }^{22}$ which may increase the severity of a COVID patient, as the presence of any other diseases has also been found to be positively associated with COVID-19 severity. ${ }^{23}$

This study found that females are less likely than males to be in critical and severe COVID statess. This finding complies with a study conducted in China in 2020, where Cai showed that males are more vulnerable than females to critical COVID-19 states owing to their predisposition to smoking. ${ }^{24}$ Males are more likely than females to be eversmokers, which increases their odds of having more smoking-related diseases, contributing to the severe and critical levels of the patients. Higher educational status is significantly related to COVID-19 severity. This finding does not comply with the findings from other studies conducted in
Sweden, Germany, and New York City, USA. Studies conducted in western countries have found that education is a protective factor against COVID-19, as the lower the educational level, the greater the exposure to gatherings and personal contacts, along with lower maintenance of hand hygiene. ${ }^{21,25,26}$ The authors of those studies also linked socio-economic status with educational level, which was followed by healthcare inequalities for people of low income categories with lower educational level. However, in Bangladesh, more severe cases are found among highly educated people than among people with lower levels of education. This is probably due to lifestyle and occupation, which are correlated with education in Bangladesh. The higher the education, the more sedentary a lifestyle is adopted. People with higher education are mostly involved in occupations that require more brain work than muscle work, which also provide them with better socio-economic security and thus encourage them to have sedentary lifestyles. ${ }^{23}$ An inactive lifestyle is a risk factor for all sorts of non-communicable diseases, which increase the case severity by acting as comorbid diseases. ${ }^{27}$ Another probable reason could be the ignorance of people with lower educational level in reporting cases or letting cases go unnoticed. However, as this finding doesn't comply with previous findings, further investigations are needed., .

Although medical professionals are the frontline workers during the COVID situation and at the highest level of risk risk because of direct contact, unemployed patients were found to be at two times higher risk of developing a severe condition. This may seem surprising, but, in line with previous research, this finding provides a good insight into the reasons. A study conducted in Germany provided the same result and, based on a previously constructed framework, they provided three reasons for this: inequalities in exposure, inequalities in vulnerability, and inequalities in care. ${ }^{28}$ According to that study, these three inequalities are linked to the socio-economic position. People with lower socio-economic position do not have access to proper healthcare, and because they do not receive timely healthcare, the COVID situation worsens among unemployed people. ${ }^{2}$ Retired people are also found to be at almost 14 times higher risk than medical professionals. Given that the retirement age in Bangladesh is 61 years, this finding is valid, as elderly age has already been proven to be a risk factor for the severity of COVID-19. 
In the non-residential urban localities and rural areas, the severity of COVID-19 was found to be almost three times and two times higher, respectively, than in the urban residential areas. As the urban residential areas are planned areas with proper healthcare facilities and lower population density, the spread of the virus is limited there and instant healthcare facilities are available to prevent the development of severe disease. In contrast, in urban nonresidential areas and rural areas, these facilities are out of the reach of most people. In addition, the maintenance of hygiene required to prevent COVID-19 is often not possible owing to the population density.

In this study, ever-married people were found to have a higher risk than never-married people of having severe and critical stages of COVID-19. This may be because ever-married people are in contact with their partners and other family members at home, which increases the exposure of ever-married people in comparison to the nevermarried group. However, previous studies have shown that smoking, which has a positive association with COVID-19 severity, has an increased rate among never-married people, probably as a result of several stress issues. ${ }^{29,30}$ This may indicate the opposite direction from the finding, and requires further investigation.

Adjusting for other factors, ethnicity was found to be significantly associated with COVID-19 severity. Chakma people and other indigenous ethnic groups were found to be at 3.43 times higher risk of having the critical stage of COVID-19. This could be due to the inaccessible food and healthcare facilities in the remote area where the indigenous people reside. Along with that, their weak strategy to prevent COVID-19 due to a lack of mass announcements and awareness in the remote areas may also be a reason. However, this finding complies with previous studies conducted on different ethnic groups in different countries and states. Studies conducted among different minority ethnic groups suggest that ethnicity and COVID-19 should be a focus for public health research area in the future. ${ }^{31-33}$

The main strength of this study is its sample size. This study was conducted by telephone, using a city corporation case-confirmed list. The study sample comprised 2022 cases covering all five stages of COVID-19. This resulted in a larger sample size than in any other study conducted on this issue. It also resulted in a good, representative data set, properly blending some of the districts of Dhaka.

A limitation of this study is that there were few representative data for different ethnic groups. In addition, in the smoker category, former smokers were included. This may have caused misclassification bias in a few cases. Also, e-cigarette use was not included in the survey, which may have led to a few more cases being missed.

\section{Conclusion}

Smoking is strongly associated with the severity of COVID-19 disease progression. This finding calls for mass awareness and cessation campaigns by governments and other organizations to maintain alertness regarding contamination by similar types of virus-borne diseases. However, many other factors have also been found to play associated roles in accelerating the severity of the disease. These factors also need immediate attention from public health professionals so that they can be investigated further and proper measures can be introduced.

\section{Ethical Approval}

The study was ethically approved by the institution's review board (IRB)/ethical review committee (ERC) of North South University, Bangladesh (Memo no. 2020/ORNSU/IRB-No. 0802).

\section{Acknowledgments}

We would like to express our sincere thanks and gratitude to the study participants for their cooperation. We are also thankful to the hospital authorities for their tremendous support during data collection.

\section{Disclosure}

The authors report no conflicts of interest in this work.

\section{References}

1. Cascella M, Rajnik M, Cuomo A, Dulebohn SC, Di Napoli R Features, Evaluation and Treatment Coronavirus (COVID-19). StatPearls Publishing; 2020. Available from: http://www.ncbi.nlm.nih.gov/ pubmed/32150360. Accessed April 11, 2021.

2. Simons D, Shahab L, Brown J, Perski O. The association of smoking status with SARS-CoV-2 infection, hospitalisation and mortality from COVID-19: a living rapid evidence review (version 6). Qeios. 2020;1-35. doi:10.32388/ujr2aw.7

3. World No Tobacco Day. Available from: https://www.who.int/cam paigns/world-no-tobacco-day. Accessed April 26, 2021.

4. World Health Organization. WHO statement: tobacco use and COVID-19. World Health Organization; 2020. Available from: https://www.who.int/news/item/11-05-2020-who-statement-tobaccouse-and-covid-19. Accessed June 29, 2021.

5. Centers for Disease Control and Prevention (CDC). People at Increased Risk of Covid-19; Published online 2020. 2019-2021. Available from: https://www.cdc.gov/coronavirus/2019-ncov/needextra-precautions/index.html. Accessed June 29, 2021.

6. World Health Organization. Smoking and COVID-19. Available from: https://www.who.int/news-room/commentaries/detail/smoking-andcovid-19. Accessed April 26, 2021. 
7. Pötschke-Langer M, Schotte K, Szilagyi T. The WHO framework convention on tobacco control. Prog Respir Res. 2015;42:149-157. doi:10.1159/000369441

8. Brake SJ, Barnsley K, Lu W, McAlinden KD, Eapen MS, Sohal SS. Smoking Upregulates Angiotensin-Converting Enzyme-2 Receptor: a Potential Adhesion Site for Novel Coronavirus SARS-CoV-2 (Covid-19). J Clin Med. 2020;9(3):841. doi:10.3390/jcm903084

9. Foundation TI. National Guidelines on Clinical Management of COVID-19; 2008:0-28.

10. Zhao Q, Meng M, Kumar R, et al. The impact of COPD and smoking history on the severity of COVID-19: a systemic review and meta-analysis. J Med Virol. 2020;92(10):1915-1921. doi:10.1002/ jmv.25889

11. Nargis N, Thompson ME, Fong GT, et al. Prevalence and patterns of tobacco use in Bangladesh from 2009 to 2012: evidence from International Tobacco Control (ITC) study. PLoS One. 2015;10 (11):1-16. doi:10.1371/journal.pone.0141135

12. Fischer F, Minnwegen M, Kaneider U, Kraemer A, Khan MMH. Prevalence and determinants of secondhand smoke exposure among women in Bangladesh, 2011. Nicotine Tob Res. 2015;17(1):58-65. doi: $10.1093 / \mathrm{ntr} / \mathrm{ntu} 129$

13. Coronavirus disease (COVID-2019) Bangladesh situation reports. Available from: https:/www.who.int/bangladesh/emergencies/corona virus-disease-(covid-19)-update/coronavirus-disease-(covid-2019)bangladesh-situation-reports. Accessed April 26, 2021

14. Gallus S, Lugo A, Gorini G. No double-edged sword and no doubt about the relation between smoking and COVID-19 severity. Eur J Intern Med. 2020;77:33-35. doi:10.1016/j.ejim.2020.06.014

15. Bangladesh Society of Medicine. 2019-nCOV (SARS-COV-2) Infection Prevention Control (IPC) and Management in Healthcare Facilities; Published online 2020.

16. Zhang JJ, Dong X, Cao YY, et al. Clinical characteristics of 140 patients infected with SARS-CoV-2 in Wuhan, China. Allergy Eur $J$ Allergy Clin Immunol. 2020;75(7):1730-1741. doi:10.1111/ all.14238

17. Zhou F, Yu T, Du R, et al. Clinical course and risk factors for mortality of adult inpatients with COVID-19 in Wuhan, China: a retrospective cohort study. Lancet. 2020;395(10229):1054-1062. doi:10.1016/S0140-6736(20)30566-3

18. Cen Y, Chen X, Shen Y, et al. Risk factors for disease progression in patients with mild to moderate coronavirus disease 2019-a multicentre observational study. Clin Microbiol Infect. 2020;26 (9):1242-1247. doi:10.1016/j.cmi.2020.05.041

19. Boehmer TK, DeVies J, Caruso E, et al. Changing Age Distribution of the COVID-19 Pandemic. MMWR Morb Mortal Wkly Rep. 2020;69(39):1404-1409. doi:10.15585/mmwr.mm6939e1
20. Cortis D. On Determining the Age Distribution of COVID-19 Pandemic. Front Public Health. 2020;8:1-3. doi:10.3389/ fpubh.2020.00202

21. Harlem G. Descriptive analysis of social determinant factors in urban communities affected by COVID-19. J Public Heal (United Kingdom). 2020;42(3):466-469. doi:10.1093/pubmed/fdaa078

22. World Health Organization. World Health Organization; 2020:1-203. Available from: https://www.who.int/emergencies/diseases/novelcoronavirus-2019/events-as-they-happen. Accessed July 31, 2020.

23. Berlin I, Thomas D, Le Faou A-L, Cornuz J. COVID-19 and smoking. Nicotine Tob Res. 2020;22(9):1650-1652. doi:10.1093/ntr/ ntaa059

24. Cai H. Sex difference and smoking predisposition in patients with COVID-19. Lancet Respir Med. 2020;8(4):e20. doi:10.1016/S22132600(20)30117-X

25. Drefahl S, Wallace M, Mussino E, et al. A population-based cohort study of socio-demographic risk factors for COVID-19 deaths in Sweden. Nat Commun. 2020;11(1):1-7. doi:10.1038/s41467-02018926-3

26. Lüdecke D, Von Dem Knesebeck O. Protective Behavior in Course of the COVID-19 Outbreak-Survey Results From Germany. Front Public Heal. 2020;8:1-8. doi:10.3389/fpubh.2020.572561

27. Vardavas CI, Nikitara K. COVID-19 and smoking: a systematic review of the evidence. Tob Induc Dis. 2020;18:1-4. doi:10.18332/ tid/119324

28. Wahrendorf M, Rupprecht CJ, Dortmann O, Scheider M, Dragano N Higher risk of COVID-19 hospitalization for unemployed: an analysis of health insurance data from 1.28 million insured individuals in Germany. Bundesgesundheitsblatt - Gesundheitsforsch Gesundheitsschutz. 2021;64(3):314-321. doi:10.1007/s00103-02103280-6

29. Lindström M. Social capital, economic conditions, marital status and daily smoking: a population-based study. Public Health. 2010;124 (2):71-77. doi:10.1016/j.puhe.2010.01.003

30. Cho HJ, Khang YH, Jun HJ, Kawachi I. Marital status and smoking in Korea: the influence of gender and age. Soc Sci Med. 2008;66 (3):609-619. doi:10.1016/j.socscimed.2007.10.005

31. Pan D, Sze S, Minhas JS, et al. The impact of ethnicity on clinical outcomes in COVID-19: a systematic review. EClinicalMedicine. 2020;23:100404. doi:10.1016/j.eclinm.2020.100404

32. Power T, Wilson D, Best O, et al. COVID-19 and Indigenous Peoples: an imperative for action. J Clin Nurs. 2020;29(1516):2737-2741. doi:10.1111/jocn. 15320

33. Pareek M, Bangash MN, Pareek N, et al. Ethnicity and COVID-19: an urgent public health research priority. Lancet. 2020;395 (10234):1421-1422. doi:10.1016/S0140-6736(20)30922-3
Journal of Multidisciplinary Healthcare

\section{Publish your work in this journal}

The Journal of Multidisciplinary Healthcare is an international, peerreviewed open-access journal that aims to represent and publish research in healthcare areas delivered by practitioners of different disciplines. This includes studies and reviews conducted by multidisciplinary teams as well as research which evaluates the results or conduct of such teams or healthcare processes in general. The journal covers a very wide range of areas and welcomes submissions from practitioners at all levels, from all over the world. The manuscript management system is completely online and includes a very quick and fair peer-review system. Visit http://www.dovepress.com/testimonials. php to read real quotes from published authors. 